\title{
ACTION OF DIMETHYL SULFOXIDE ON FINKLEMAN PREPARATION
}

\author{
G. ACHARI AND G.N. SINHA \\ Department of Pharmacology, P. W. Medical College, Palna, India \\ Received for publication August 26, 1967
}

\begin{abstract}
Dimethyl sulfoxide (DMSO) was first prepared by Alexander Saylzeff in 1866 and is now obtained from waste product in paper manufacture. Though primarily used as an unusual solvent, the chance discovery of its skin penetrability triggered off series of investigations about the clinical usefulness of the agent and its various biological actions (1). In light of the forementioned work, it was considered worthwhile to investigate the action of DMSO on Finkleman preparation of rabbit ileum.
\end{abstract}

\section{MATERIALS AND METHODS}

The method originally employed by Finkleman (2) and modified by Achari and Dutta (3), was used in the current study. Adult rabbits of mixed strain were killed by blow on the head and bled to death by severing the carotid arteries. About $5 \mathrm{~cm}$ piece of ileum was separated from the rest of it by transverse cuts and the contents removed by syringing with warm tyrode solution. The cuts were continued for about 8 to $10 \mathrm{~cm}$ along the mesentery on each side of the blood vessels supplying the part of ileum. The mesentery was then cut across and the preparation now consisting of the ileum, the blood vessels and the nerves running along side the latter (the last two mentioned, enclosed in the mesentery) were transferred to Tyrode solution. A piece of thread was tied to the free end of the mesentery and the preparation was set up in the usual isolated tissue bath (Magnus method) containing Tyrode solution at $36 \mathrm{C}$. The tracings were recorded on a slow moving smoked drum with the help of aluminium frontol writing lever. The sympathetic nerves were stimulated by gently pulling out the mesentery from the bath and laying it across the electrodes. Care was taken to keep the negative electrode (which was the stimulating electrode) near the ileum. The rate of stimulation was 60 per second, each stimulus being of 0.5 millisecond duration. Supramaximal voltage was used throughout the experiment, the nerves being stimulated for 30 seconds with rest periods of at least 10 minutes.

\section{RESULTS}

Stimulation of the nerves caused inhibition of the rhythmic contractions of the ileum, which returned to normal in "step ladder fashion" when the stimulus ceased. Addition of noradrenaline to the bath produced similar inhibition of the movement which returned to normal when the bath was washed out. It was found that $0.2 \mu \mathrm{g} / \mathrm{ml}$ of noradrenaline in bath fluid gave a tracing closely similar to that obtained by electrical stimulation of 


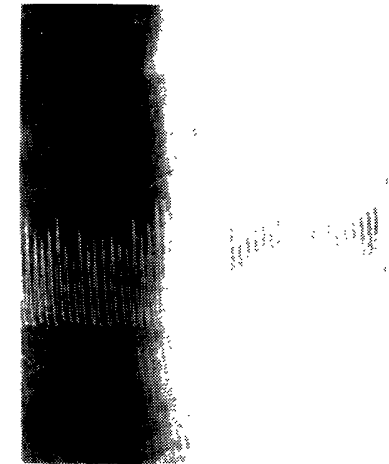

Normal $15 \mathrm{~min}$ DMSO
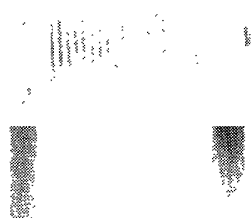

$30 \mathrm{~min}$
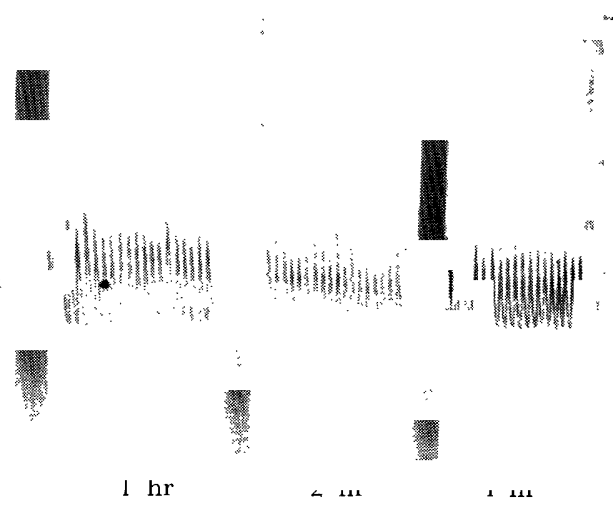

FIG. 1. Showing the effects of DMSO on the rhythmic movements of rabbit ileum.
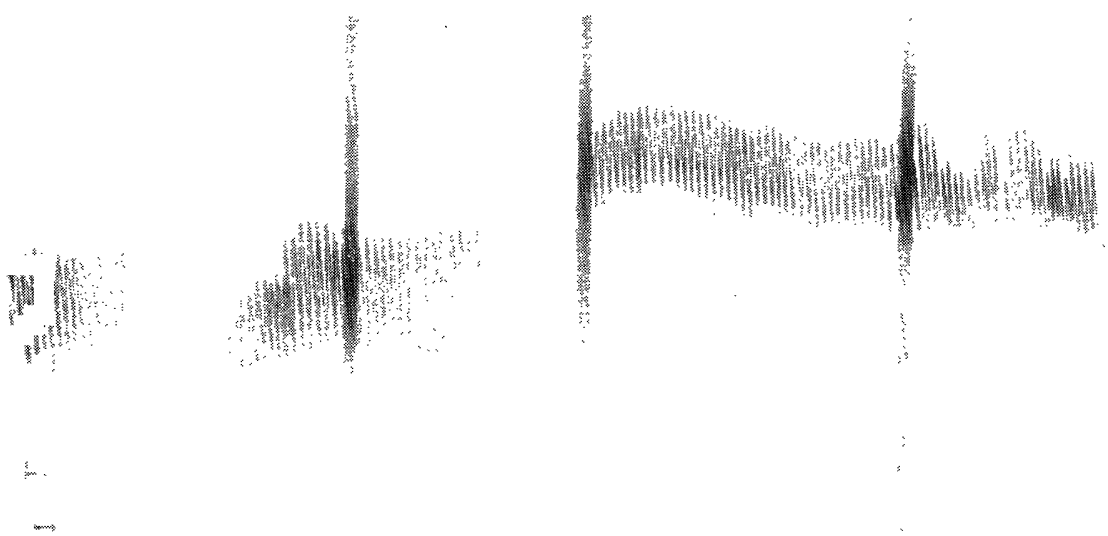

A

B

Li

$\nu$

FIG. 2. Showing the effects of DMSO on the Finkleman preparation of rabbit ileum. Mesenteric nerves stimulated for 30 seconds (thick lines). Time $=30$ seconds.

The effects of stimulation (A) and $(0.2 \mu \mathrm{g} / \mathrm{ml})$ noradrenaline. DMSO $(0.44 \%)$ completely blocked the inhibitory effects of stimulation in 2 hours $(G)$, but the inhibitory action of noradrenaline was not impaired (D).

the sympathetic nerves.

In order to find out whether DMSO itself had any action on the rhythmic movements of rabbit ileum, the drug was left in contact with the tissue in Magnus bath for about 6 hours. The result is shown in Fig. 1. The recording as depicted in Fig. 1 shows that DMSO does not in any way affect the rhythmicity and tone of the rabbit ileum.

In a further series of experiments, dimethyl sulfoxide was added to the bath fluid in gradually increasing concentration and the nerves were stimulated every 30 minutes for 3 hours or till the nerve was blocked. It was found that $0.44 \%$ dimethyl sulfoxide in the bath fluid completely prevented the intestinal inhibition produced by electrical stimulation in 2 hours time. Addition of noradrenaline thereafter (to give a concentration of $0.2 \mu \mathrm{g} / \mathrm{ml}$ of bath fluid) caused inhibition of the movements which returned to normal when the bath fluid was changed (Fig. 2). 


\section{DISCUSSION}

Since noradrenaline continued to act even after the nerve-induced inhibition was prevented by DMSO, it was concluded that it (DMSO) did not block the adrenergic receptors and that the action of the compound was due either to the blockade of the sympathetic nerves or to the prevention of the release of the transmitters at the sympathetic nerve endings. Davis and Clemons (4) had demonstrated that the $10 \%$ (DMSO) exhibited a nerve blocking effect as indicated by the elevation of rheobase. Later, Davis et al. (5) showed that dimethyl sulfoxide acted as a typical moderate procoagulant in plasma recalcification tests and that at concentration of $1 \%$ or less it accelerated gel formation. They also observed that 40 to $50 \%$ DMSO completely blocked the motor nerves in frog nerve-muscle preparation. They interpreted both these changes in terms of the charge and hydration on the proteins involved-fibrinogen and nerve proteins respectively. The action is similar to that of dehydrating alcohols like ethanol, which has a definite nerve blocking property. Sams (6), utilizing frogs sciatic nerve brought forward evidence that $6 \%$ DMSO significantly slowed the conduction velocity and that the effect was totally reversed when the drug was washed out within 2 hours. He suggested that though the compound slowed conduction, its action on the skeletal, smooth and cardiac muscles are due to mechanism other than an effect on the nerve itself. In the present study evidence has been found that DMSO blocks conduction along the autonomic nerves.

\section{SUMMARY}

$0.44 \%$ concentration of dimethyl sulfoxide blocked the conduction along the sympathetic nerves after exposure for 2 hours. The studies were carried out on Finkleman preparation as modified by Achari and Dutta.

\section{REFERENCES}

1) Sams, W.M. Jr., Carrol, N.V. and Crantz, P.L.: Proc. Soc. exp. Biol. Med. 122, 103 (1966)

2) Finkleman, B.: J. Physiol. 70, 145 (1930)

3) Achari, G. and Dutta, R.K.: J. Indian M.A. 36, 323 (1961)

4) Davis, N.L. and Clemons, A.L.: Personal communication to Sams, W.M. Jr. in Ann. N.Y. Acad. Sci. 141, $242(1967)$

5) Davis, H.L., Davis, N.L. and Clemons, A.L.: Ann. N.Y. Acad. Sci. 141, 310 (1967)

6) SAms, W.M. Jr.: Ibid. 141, 242 (1967) 